\title{
Using Morningstar's Analytical Measures to Evaluate Investment Recommendations Made by Consumer Reports
}

\author{
C. Edward Chang ${ }^{1} \&$ Thomas M. Krueger ${ }^{2}$ \\ ${ }^{1}$ College of Business, Missouri State University, Springfield, Missouri, U.S.A. \\ ${ }^{2}$ College of Business Administration, Texas A\&M-Kingsville, Kingsville, Texas, U.S.A. \\ Correspondence: Thomas M. Krueger, College of Business Administration, Texas A\&M-Kingsville, Kingsville, \\ TX, 78363, U.S.A. Tel: 1-361-397-3787. E-mail: thomas.krueger@tamuk.edu
}

Received: November 17, 2012

Accepted: January 2, 2013

Online Published: February 22, 2013

doi:10.5539/ijef.v5n3p1

URL: http://dx.doi.org/10.5539/ijef.v5n3p1

\begin{abstract}
Instead of its typical analysis of automobiles and household gadgets, Consumer Reports ventured into the murky world of predicting investments performance in 2005 and 2007. Enough time has passed since these recommendations to conduct a rigorous investigation of Consumer Reports' success. This study analyzes recommendations through examination of return, risk, and risk-adjusted return using the popular Morningstar ratings. Consumer Reports' choices will be judged in relationship to mutual funds in the same category and index funds. It appears as though Consumer Reports provided a valuable service to its investing readership both times.
\end{abstract}

Keywords: mutual funds, investment recommendations, investment performance, Morningstar, Consumer Reports

\section{Introduction}

\subsection{Consumer Reports}

Making wise investment decisions is one of the most critical and challenging decisions faced by individuals. One way to maintain and build wealth is through astute selection of mutual funds. In 2012, 53.8 million households, which is 44.4 percent of all households, owned mutual fund (Investment Company Institute, 2012). The objective of this research is to evaluate the mutual fund recommendations made by Consumer Reports in terms of return, risk, and risk-adjusted return using the popular Morningstar rankings.

Consumer Reports is a monthly publication of Consumers Union, a New York-based association of engineers, professors, labor leaders, and journalists. Its claim to fame lies in the quality of its articles, based on independent analysis of a wide variety of consumer goods. It does not print advertisements or accept free samples, allowing Consumers Union to claim that it is an unbiased, independent rating agency. Since its origin in 1933, Consumer Reports has only made two sets of recommendations regarding investment choices, one in 2005 and another in 2007.

This investigation analyzes Consumer Reports' ability to adapt its highly-regarded analytical skills to investment choices. Morningstar's proprietary return, risk, and rating (also known as "star") rankings are used to judge the value of using Consumer Reports as an investment advisor. Significant findings indicate that the information used by Consumer Reports is not fully reflected in stock prices. Instead of attempting to determine and then adopt the investment criteria employed by Consumer Reports, investors may be able to simply use Consumer Reports' recommendations as the basis of their investment selection.

\subsection{Literature Review}

\subsubsection{Performance of Consumer Reports' Recommended Mutual Funds}

Two prior articles have evaluated the return performance of Consumer Reports' recommended mutual funds. Interestingly, each article only studied one mutual fund recommendation. Index Investor (undated) studies the period prior to the first recommendation, while Chen (2011) examines the period surrounding the second recommendation. Studying the 1995 to 2004 period, Index Investor finds that the 52 funds in the 2005 Consumer Reports article had an average alpha of only $0.17 \%$, and many were negative. This led Index Investor to the conclusion that Consumer Reports' 2005 mutual fund recommendation was "a big mistake by an organization that is generally extremely reliable." By comparison our study examines subsequent investment returns, which would be available to investors. 
Chen (2011) examines 60 mutual funds presented in the Consumer Reports' February 2007 issue. The November 30, 2006 and September 30, 2008 time periods were analyzed in her study, in order to exclude the major declines that occurred in the stock market during the last quarter of 2008. In addition to reporting on a wide variety of fund characteristics, Chen studies return performance to determine whether Consumer Reports is a reliable information source for investors seeking to purchase mutual funds. Based on two limited sample periods, including time both before and after fund recommendation, Chen concludes that Consumer Reports is not a good investment advisor. However, her post-publication sample period is too short to effectively test the utility of using Consumer Reports' 2007 recommendation.

Extensive study has been done of the relationship between mutual fund advertising and rankings as well as investor reaction to a mutual fund being included in the rankings. Reuter and Zitzewitz (2006) report a positive relationship between advertising expenditures and fund recommendations by personal finance publications. In order to adjust for the potential that past fund advertising has created a demand for articles concerning advertisers, as exposed by George and Waldfogel (2003), Reuter and Zitzewitz conduct comparisons across personal finance publications. Between 1998 and 2002, Reuter and Zitzewitz find that 83.8 percent of the mutual fund families that spent over $\$ 1$ million in Money magazine advertising increased the probability of receiving a positive mention by twenty percent. However, Reuter and Zietzewitz' findings do not reveal a correlation between advertising and subsequent returns. Nonetheless, investors respond to fund mentions in Consumer Reports with an economically significant increase in fund investment. These findings are consistent with Sirri and Tufano's (1998) and Jain and Wu's (2002) findings that mutual funds receiving more media attention receive correspondingly higher inflows, because investors have lower search costs.

Our research is a better measure of the value of Consumer Reports' recommendations for six reasons. One, we use a longer sample period as the investment time horizon. Two, we do not exclude any expansionary or recessionary stock market period. Three, we include both the 2005 and 2007 Consumer Reports' recommendations in our analysis. Four, use of Morningstar star statistics brings with it some additional advantages, which will be outlined in the next section. Five, unlike Chen's study of a fund's net assets, manager tenures, and the like, we focus purely on returns and risk because these are the factors that impact investor wealth. Six, we do not deviate from a focus on return performance to consider such issues as flows to and from the fund or perception of fund performance based on the provision of supplemental information as done by Kozup, Howlett, and Pagano (2008). After all, the core issue is the economic benefit of using a given source of investment information. Therefore, we believe that this analysis presents a clearer, more comprehensive investigation of Consumer Reports' recommendations.

\subsubsection{Morningstar and the Benefits of Using Its "Star" Rating System}

Some information is provided about Morningstar, Inc. because it is the supplier of the data used in this analysis. Like Consumer Reports, Morningstar is a widely-respected, independent investment research company. The Chicago-based firm provides analysis of over 350,000 investments, and is most well known for its analysis of stocks and mutual funds (Morningstar, 2012). The most popular information produced by Morningstar is its star ranking system. There are actually three different rankings assigned by Morningstar based on a fund's monthly performance including the effects of sales charges, loads, and redemption fees. Unfortunately, Morningstar's assessment process is proprietary and not disseminated. Morningstar reportedly places more emphasis on downward variation and rewards consistent performance, which are both prized by mutual fund investors. Information shared with the general public is that the Morningstar ranking system is based on performance during the past three, five, and ten years (where available), with more import given to recent results. Hence, it focuses on the period since Consumer Reports made its recommendations. It also states that the top $10 \%$ of funds in each category receive five stars, the next $22.5 \%$ receive four stars, the middle $35 \%$ receive three stars, the next $22.5 \%$ receive two stars, and the bottom $10 \%$ receive one star, providing a crude bell-shaped distribution. Despite these limitations, many mutual funds report their performance using Morningstar's star rating system (for example Aston Asset Management (2012) and T. Rowe Price (2012)). In the Wall Street Journal's Investing in Funds \& ETFs quarterly analysis in early 2013, Morningstar's star rankings were viewed as being both well-known and a "straight-forward and intuitive approach for gauging fund performance" (Espinoza, 2013). The article goes on to warn readers that other rating systems, such as Morningstar's gold, silver, bronze, neutral and negative award system, are based on human judgment.

Del Guercio and Tkac (2008) provide evidence that money flowing to mutual funds responds to changes in Morningstar ratings. However, Morningstar rankings are not infallible. In fact, while money is pouring into the funds with four and five stars, Morningstar's own research shows that its stars are worth little as investment guides. According to Quinn (2010), this is especially true of market turns. During tranquil years, there is a limited amount of forecasting ability arising from Morningstar's stars. For instance, four-star performance tops that of the three stars by 0.5 percentage points or less. However, any individual fund, in either group, could do 
much better or much worse. During years of market changes, the star pattern is in disarray. For instance, among bond funds and balanced stock-and-bond funds, lowly one-star and two-star funds did far better in the following two years than the five-star funds. Russel Kinnel (2009), Morningstar's director of mutual fund research observes lower returns to funds with more stars in the high-yield bond, technology, high price/earnings ratio, and large growth sectors. In short, Morningstar is a respected, valid measure of past performance, which is the focus of this study, without any guarantee regarding future performance.

\section{Method}

\subsection{Consumer Reports' Recommendations}

Seventy mutual funds were recommended in Consumer Reports' March 2005 issue. In the February 2007 issue, sixty funds were recommended. Forty-six of the funds proposed in 2007 were new funds. Four of the seventy funds recommended in 2005 (CR 2005) and two of the new funds recommended in 2007 (CR 2007) have closed, leaving sixty-six and forty-four funds, respectively. We focus on the new funds in the 2007 recommendation because they represent new Consumer Reports' selections and why the publication felt an updated recommendation was necessary. Consumer Reports does not explicitly tell readers to replace their 2005 choices with the 2007 funds, and there is no overlap of mutual funds in our analysis.

Fourteen Morningstar categories are represented by the sixty-six remaining CR 2005 funds. Eighteen Morningstar categories are represented by the forty-four CR 2007 funds. The biggest change in new funds chosen is that the CR 2007 set includes selections from five foreign mutual funds categories (i.e., large blend, large growth, large value, small/mid value, and world allocation), and a few domestic sectors (i.e., financial, utilities).

Out of the 9,213 funds in existence in 2005, Consumer Reports picked 70 funds, or 0.76 percent of the possible total. In 2007, out of the 11,488 funds, Consumer Reports picked 44 new funds, or 0.38 percent, in 2007. Obviously, the chosen mutual funds are a very select group.

\subsection{Mutual Fund Data and Methodology}

All data for individual mutual funds and category averages of mutual funds were collected from Morningstar's Principia database as of March 31, 2010. The return performance of the Consumer Reports' selections is compared to the performance of the category average and a Vanguard index fund in each Morningstar category. The comparative numbers are only based on those categories wherein Consumer Reports found good fund investment choices. For instance, CR 2005's performance benchmarks include performance of the real estate sector, but not the foreign large blend sector.

Using Morningstar has the additional benefit of benefiting from its categorizing of mutual fund type on the basis of the securities in each portfolio. A fund's prospectus may not be a completely accurate description of how the fund actually invests. Given its excellent reputation and widespread use by investors, we rely on Morningstar for proper categorization of funds.

A paired t-test is the primary statistical testing method used in this report. There is a matching of the average return of the mutual funds chosen by Consumer Reports and the average of the mutual funds placed in the same category by Morningstar. Measurements are aggregated across fund categories. The null hypothesis is always equality of means, with the alternative hypothesis being inequality of means. The lower the t-test statistics the greater the apparent skills of the Consumer Reports investment research team.

\section{Results}

\subsection{Morningstar Return Rankings}

Morningstar helps investors gain an understanding of how mutual funds fall within a normal distribution by presenting its own performance metric. With only a five-step scale, and clustering of funds around the mean, the Morningstar ranking provides an impression of how a given fund performed relative to a crude bell-shaped curve and thereby provides additional insight to the investor. An average Morningstar return rankings is 3 , as illustrated by this value found in the "Category Averages" row for all Consumer Reports recommendations in Table 1.

Across the Consumer Reports fund selections, the 5.00 ranking for the CR 2007 recommendation of foreign large blend funds indicates that this choice was in the top 10 percent of all funds in this category. Among the CR 2005 selections, the best recommendations were the two small value funds, which had an average Morningstar return ranking of 3.50 during the April 2007 to March 2010 period, and 4.00 average during the April 2005 to March 2010 period. The 4.00 value indicates that this selection is within the best 10.01 to 32.50 percent of funds in the small value category. 
Table 1. Morningstar return rankings

\begin{tabular}{|c|c|c|c|}
\hline \multirow[b]{3}{*}{ Morningstar Categories } & \multicolumn{3}{|c|}{ Investment Time Horizon } \\
\hline & \multicolumn{2}{|c|}{2005 CR Recommendations } & \multirow{2}{*}{$\begin{array}{c}2007 \text { CR Recommendations } \\
\text { 3 Years } \\
\end{array}$} \\
\hline & 3 Years & 5 Years & \\
\hline Conservative Allocation & & & 4.50 \\
\hline Financial & & & 3.00 \\
\hline Foreign Large Blend & & & 5.00 \\
\hline Foreign Large Growth & & & 2.00 \\
\hline Foreign Large Value & & & 5.00 \\
\hline Foreign Small/Mid Value & & & 5.00 \\
\hline Health & 3.00 & 3.00 & \\
\hline Industrials & 3.00 & 3.00 & \\
\hline Large Blend & 3.13 & 3.38 & 2.50 \\
\hline Large Growth & 3.50 & 3.50 & \\
\hline Large Value & 3.63 & 3.44 & 3.50 \\
\hline Mid-Cap Blend & 3.88 & 3.63 & 2.50 \\
\hline Mid-Cap Growth & 3.00 & 2.00 & \\
\hline Mid-Cap Value & 3.00 & 3.00 & 3.50 \\
\hline Moderate Allocation & 3.36 & 3.82 & 3.20 \\
\hline Natural Resources & 3.00 & 2.00 & 2.00 \\
\hline Real Estate & 2.67 & 3.00 & \\
\hline Small Blend & 3.60 & 3.20 & 3.80 \\
\hline Small Growth & & & 3.00 \\
\hline Small Value & 3.50 & 4.00 & 3.00 \\
\hline Utilities & & & 3.00 \\
\hline World Allocation & & & 3.50 \\
\hline World Stock & 3.00 & 2.50 & 2.60 \\
\hline Average & 3.23 & 3.11 & 3.37 \\
\hline \multicolumn{4}{|c|}{ Panel B. Benchmark Portfolio Morningstar Return Ratings and statistical significance of Consumer Reports' recommendations } \\
\hline Category Averages & 3.00 & 3.00 & 3.00 \\
\hline T-test statistic & $0.012 * *$ & 0.264 & $0.061^{*}$ \\
\hline Vanguard index funds & 3.36 & 3.50 & 3.61 \\
\hline T-test statistic & 0.230 & $0.047 * *$ & 0.130 \\
\hline
\end{tabular}

Notes: ***,**, *: Significant at the $0.01,0.05$, and 0.10 level.

A good example of the value of Morningstar rankings is provided by the small value funds. Their average annual return was a loss of 0.61 percent, which seems unremarkable. However, with a Morningstar ranking of 4.0, on a relative basis the performance of CR 2005's recommendations in the small value category were well above normal.

Another good example of the relevant, additional informative aspect of Morningstar's return rankings can be witnessed in the mid-cap growth category. The performance of this fund was one of the top two performers among Consumer Reports' choices over three years and had mid-level performance over five years. However, in Table 1, one can see that the Morningstar return ranking is only an average 3.00 stars during the shorter period and a below-average, 2.00 stars during the longer period.

Average Morningstar return rankings for Consumer Reports' recommendations fall between the category averages and Vanguard index fund benchmark in every examined instance. The CR 2005 and CR 2007 instances were significantly better at the category average at the 0.01 and 0.10 levels, respectively. However, if one would have invested in the CR 2005 funds over the April 2005 to March 2010 period, their performance would have been worse than the Vanguard index fund benchmark at the 0.05 level. 


\subsection{Morningstar Risk Rankings}

Findings based on Morningstar's risk rankings are an alternative to the common analysis of standard deviations and beta. One advantage of using Morningstar's risk rankings, displayed in Table 2, is that they are a standardized measure of risk, as implied by the 3.00 values found in the "Category Averages" row. Furthermore, as described above, negative mutual fund return variance is up-weighted in comparison to upside risk. Undesirable higher levels of risk result in higher Morningstar risk rankings. With nine risk rankings below 2.75 versus none above 3.25 , it is not surprising that that CR 2005 funds have an average of 2.40 . This is significantly lower than the 3.00 category average and 3.64 Vanguard index fund benchmark at the 0.01 level.

Table 2. Morningstar risk rankings

\begin{tabular}{|c|c|c|c|}
\hline \multicolumn{4}{|c|}{ Panel A. Results within Morningstar categories and average of category results } \\
\hline \multirow[b]{3}{*}{ Morningstar Categories } & \multicolumn{3}{|c|}{ Investment Time Horizon } \\
\hline & \multicolumn{2}{|c|}{2005 CR Recommendations } & \multirow{2}{*}{$\begin{array}{c}2007 \text { CR Recommendations } \\
3 \text { Years }\end{array}$} \\
\hline & 3 Years & 5 Years & \\
\hline Conservative Allocation & & & 3.50 \\
\hline Financial & & & 3.00 \\
\hline Foreign Large Blend & & & 2.00 \\
\hline Foreign Large Growth & & & 3.00 \\
\hline Foreign Large Value & & & 1.00 \\
\hline Foreign Small/Mid Value & & & 1.00 \\
\hline Health & 2.00 & 2.00 & \\
\hline Industrials & 2.00 & 2.00 & \\
\hline Large Blend & 3.13 & 3.13 & 3.00 \\
\hline Large Growth & 2.00 & 2.00 & \\
\hline Large Value & 2.81 & 2.75 & 3.00 \\
\hline Mid-Cap Blend & 2.50 & 2.50 & 3.50 \\
\hline Mid-Cap Growth & 3.00 & 3.00 & \\
\hline Mid-Cap Value & 3.00 & 2.80 & 3.00 \\
\hline Moderate Allocation & 2.82 & 2.91 & 3.14 \\
\hline Natural Resources & 2.00 & 2.00 & 1.50 \\
\hline Real Estate & 2.00 & 1.67 & \\
\hline Small Blend & 1.80 & 1.60 & 2.40 \\
\hline Small Growth & & & 1.00 \\
\hline Small Value & 2.00 & 2.00 & 2.33 \\
\hline Utilities & & & 2.00 \\
\hline World Allocation & & & 3.00 \\
\hline World Stock & 2.50 & 2.50 & 2.80 \\
\hline Average & 2.40 & 2.35 & 2.45 \\
\hline \multicolumn{4}{|c|}{ Panel B. Benchmark Portfolio Morningstar Risk Ratings and statistical significance of Consumer Reports' recommendations } \\
\hline Category Averages & 3.00 & 3.00 & 3.00 \\
\hline T-test statistic & $0.000^{* * *}$ & $0.000^{* * *}$ & $0.007^{* * *}$ \\
\hline Vanguard index funds & 3.64 & 3.43 & 3.67 \\
\hline T-test statistic & $0.000 * * *$ & $0.000^{* * *}$ & $0.001 * * *$ \\
\hline
\end{tabular}

Notes: ***,**,*: Significant at the $0.01,0.05$, and 0.10 level.

Expanding the sample period to five years slightly reduces the CR 2005 average Morningstar risk rankings. Only the moderate allocation category experiences a risk ranking rise. Although the Vanguard index fund benchmark's Morningstar risk rankings is also lower over the longer period, the CR 2005 recommendation is still superior, in terms of having a lower level of risk, at the 0.01 level.

Similar comments can be made for the CR 2007 funds. At 1.00, the foreign large value fund TBGVX (Tweedy Browne Global Value), foreign small/mid value fund SGOVX (First Eagle Overseas), and two small growth 
funds, BGRFX (Baron Growth Retail) and SAGWX (Sentinel Small Capital), have the lowest possible Morningstar risk ranking within their respective categories. Only the CR 2007 funds in the conservative allocation and mid-cap blend categories exceed the 3.0 average star value. However, choices in these categories have an average Morningstar risk ranking of only 3.50 stars. The resulting low Morningstar risk ranking is significantly less than the category average or Vanguard index fund benchmark at the 0.01 level.

\subsection{Morningstar Rating Rankings}

The widely-distributed Morningstar rating rankings are a function of both the Morningstar return and Morningstar risk rankings. As before, Morningstar specifies a value of 3.00 as the typical value, which is exemplified by the value of 3.00 found in the "Category Averages" row. Higher star frequency values in Table 3 are preferred.

Over the April 2007 to March 2010 period, CR 2005 recommendation provide a Morningstar rating ranking exceeding 3.00 nine times. Only the mid-cap value fund has a Morningstar rating ranking less than 3.00. Though not excessively large at 3.32, the CR 2005 Morningstar ratings over the three-year period are significantly higher than the category average at the 0.01 level and the Vanguard index fund benchmark at the 0.10 level.

Extending the investment period to April 2005 through March 2010 enhances the Morningstar rating ranking to 3.47. Morningstar rating rankings of 4.00 points are earned by CR 2005 funds in the health, industrials, large growth, and small value categories. Only the mid-cap value fund, at 2.60 registers a value less than 3.00. Consequently, CR 2005 funds exceed their category average at the 0.01 level and are no longer underperforming the Vanguard index fund benchmark, as observed in Table 1.

The best average Morningstar rating rankings are earned by the CR 2007 funds, with an average value of 3.57. Leading the way were the foreign large blend, foreign large value, and foreign small/mid value categories, with Morningstar rating rankings of 5.00, the highest possible score. With only two individual category Morningstar rating rankings less than 3.00, the average CR 2007 fund average is statistically better than the category average at the 0.01 level. Although the CR 2007 Morningstar return ranking was 0.24 lower than the Vanguard index fund benchmark, as shown at the bottom right of Table 1, the CR 2007 Morningstar rating ranking is higher by 0.13 . Not significant, but not a bad choice!

\section{Conclusion}

Our research generally supports the utilization of Consumer Reports in mutual fund selection. Morningstar rankings were used to provide an impression of the relative performance of CR funds on a return, risk, and risk-adjusted return basis. These findings support Consumer Reports' claim regarding an ability to select funds with superior performance when compared to Morningstar category averages. Whereas, Consumer Reports' 2005 recommendation earned a lower Morningstar return ranking than Vanguard index funds in one instance, Consumer Reports' selections had significantly lower risk in all comparisons. In combination, there was a limited amount of dominance by the Consumer Reports' selections on a risk-adjusted return, Morningstar rating basis.

As of early-2013, Consumer Reports has not published a follow-up listing to its 2007 recommendations. This research implies that additional recommendations are likely to be of value to the investors and Consumer Reports' readers. New Consumer Report investment recommendations, as well as the predictive power of the 2005 and 2007 recommendations over longer periods of time, would be a fertile area for future research. 
Table 3. Morningstar rating rankings

\begin{tabular}{|c|c|c|c|}
\hline \multicolumn{4}{|c|}{ Panel A: Results within Morningstar categories and average of category results } \\
\hline \multirow[b]{3}{*}{ Morningstar Categories } & \multicolumn{3}{|c|}{ Investment Time Horizon } \\
\hline & \multicolumn{2}{|c|}{2005 CR Recommendations } & \multirow{2}{*}{$\begin{array}{c}2007 \text { CR Recommendations } \\
3 \text { Years } \\
\end{array}$} \\
\hline & 3 Years & 5 Years & \\
\hline Conservative Allocation & & & 4.50 \\
\hline Financial & & & 3.00 \\
\hline Foreign Large Blend & & & 5.00 \\
\hline Foreign Large Growth & & & 3.00 \\
\hline Foreign Large Value & & & 5.00 \\
\hline Foreign Small/Mid Value & & & 5.00 \\
\hline Health & 3.00 & 4.00 & \\
\hline Industrials & 3.00 & 4.00 & \\
\hline Large Blend & 3.13 & 3.25 & 3.00 \\
\hline Large Growth & 3.50 & 4.00 & \\
\hline Large Value & 3.56 & 3.56 & 3.50 \\
\hline Mid-Cap Blend & 3.88 & 3.88 & 2.50 \\
\hline Mid-Cap Growth & 3.00 & 3.00 & \\
\hline Mid-Cap Value & 2.80 & 2.60 & 3.50 \\
\hline Moderate Allocation & 3.45 & 3.55 & 3.29 \\
\hline Natural Resources & 3.00 & 3.00 & 3.00 \\
\hline Real Estate & 3.33 & 3.00 & \\
\hline Small Blend & 3.80 & 3.80 & 4.00 \\
\hline Small Growth & & & 4.00 \\
\hline Small Value & 3.50 & 4.00 & 3.00 \\
\hline Utilities & & & 3.00 \\
\hline World Allocation & & & 3.25 \\
\hline World Stock & 3.50 & 3.00 & 2.80 \\
\hline Average & 3.32 & 3.47 & 3.57 \\
\hline \multicolumn{4}{|c|}{ Panel B: Benchmark Portfolio Morningstar Ratings and statistical significance of Consumer Reports' recommendations } \\
\hline Category Averages & 3.00 & 3.00 & 3.00 \\
\hline T-test statistic & $0.002 * * *$ & $0.002 * * *$ & $0.004 * * *$ \\
\hline Vanguard index funds & 3.14 & 3.50 & 3.44 \\
\hline T-test statistic & $0.080^{*}$ & 0.437 & 0.232 \\
\hline
\end{tabular}

Notes: ***,**, *: Significant at the $0.01,0.05$, and 0.10 level.

\section{References}

Aston Asset Management. (2012, March 31). Morningstar Ratings \& Rankings. Retrieved from http://astonfunds.com/performance-assets/morningstar

Chen, H. (2011). Analysis of Consumer Reports' Recommended Mutual Funds Compared to Actual Performance. Journal of Financial Services Marketing, 16(1), 42-49. http://dx.doi.org/10.1057/fsm.2011.5

Consumer Reports. (2005, March). Stock Mutual Funds: 70 All-weather Winners. Consumer Reports, 28-33.

Consumer Reports. (2007, February). 60 Funds you can count on. Consumer Reports, 18-22.

Consumer Reports. (2011, August 12). About US. Retrieved from http://www.consumerreports.org/cro/aboutus/mission/overview/index.htm

Del Guercio, D., \& Tkac, P. (2008). Star Power: The Effect of Morningstar Ratings on Mutual Fund Flow. Journal of Financial and Quantitative Analysis, 43(4), 907-936. http://dx.doi.org/10.1017/S0022109000014393

Espinoza, J. (2013, January 7). Ratings Game: What Do Those Stars and Fund Awards Mean? Wall Street Journal, p. R1.

George, L., \& Waldfogel, J. (2003). Who Affects Whom in Daily Newspaper Markets? Journal of Political Economy, 111(4), 765-784. http://dx.doi.org/10.1086/375380

Investment Company Institute. (2012). Characteristics of Mutual Fund Investors. ICI Research Perspective, $18(7), 1-16$. 
Jain, P. C., \& Wu, J. S. (2002). Truth of Mutual Fund Advertising: Evidence on Future Performance and Fund Flows. Journal of Finance, 55(2), 937-958. http://dx.doi.org/10.1111/0022-1082.00232

Kinnel, R. (2009, November 30). Star Rating at its Best and Worst. Morningstar. Retrieved from http://corporate.morningstar.com/us/documents/MethodologyDocuments/ResearchStudies/Star_Rating_Fun ds_Reprint.pdf

Kozup, J., Howlett, E., \& Pagano, M. (2008). The Effects of Summary Information on Consumer Perception of Mutual Fund Characteristics. Journal of Consumer Affairs, 42(1), 37-59. http://dx.doi.org/10.1111/j.1745-6606.2007.00093.x

Morningstar. (2012, May 1). Independent. Insightful. Trusted. Retrieved from http://corporate.morningstar.com/us/asp/subject.aspx?xmlfile=178.xml

Quinn, J. (2010, May 6). Morningstar Rankings Fail Mutual Fund Investors. CBS News. Retrieved from http://www.cbsnews.com/8301-505123_162-41240156/morningstar-star-rankings-fail-mutual-fund-investors

Reuter, J., \& Zitzewitz, E. (2006). Do Ads Influence Editors? Advertising and Bias in the Financial Media. Quarterly Journal of Economics, 121(1), 197-227. http://dx.doi.org/10.1093/qje/121.1.197

Sirri, E., \& Tufano, P. (1998). Costly Search and Mutual Fund Flows. Journal of Finance, 53(5), 1589-1622. http://dx.dot.org/10.111/0022-1082.00066

T. Rowe Price. (2012, March 31). Mutual Funds Rated Four Stars or Five Stars by Morningstar. Retrieved from http://individual.troweprice.com/public/Retail/Mutual-Funds/Our-Mutual-Fund-Family/Funds-Rated-4-and5-Stars-by-Morningstar?adcode=7209\&PlacementGUID=C9F68E39-B059-417C-A38F-1E920BCB0C5D

The Index Investor. (undated). Consumer Reports: Mutual Fund Review-Critique. Retrieved from $\mathrm{http}: / /$ www.indexinvestor.com/Free/consumerReports.php 